\title{
Library Services for Youth with Autism
}

\author{
Dr. Lesley S. J. Farmer \\ Professor of Librarianship \\ California State University, Long Beach \\ USA
}

\begin{abstract}
At least 1 in 166 children are born with Autistic Spectrum Disorder (ASD), but few school libraries provide resources and services explicitly targeting this population. This paper explains the characteristics and educational challenges of children with ASD; and provides ways to create an inclusive library environment that offers a rich variety of resources and services that engage these children. Tips for training library staff relative to $A S D$ are also given.
\end{abstract}

Autism, inclusion, technology

\section{Introduction}

Autism Spectral Disorder is now the second most common serious developmental disability after mental retardation/intellectual impairment. While autistic children are increasingly mainstreamed into the public school K-12 environment, little curricular attention is paid to meet their needs. Few U. S. libraries have documented instances where children with autism are being served, although a significant need has been identified to create a school library curriculum program plan by adapting existing school resources; concurrently, sensitivity training for library staff needs to be provided. This book focuses on ways that youth-serving librarians can meet the needs of youth (children and teens) with autism through welcoming facilities, inclusive learning activities, informed aid, and targeted training.

\section{What is Autism Spectrum Disorder?}

Autism has been documented as a formal spectrum of disabilities for approximately sixty years. As awareness has grown, the number of children with autism has risen from 5 out of every 10,000 births in early studies to 1 per 150 births today according to Centers for Disease Control and Prevention (2007). Autism Spectrum Disorder (ASD) refers to five pervasive developmental disorders: Autistic Disorder, Rett's Syndrome, Childhood Disintegrative Disorder, Asperger Syndrome, and Pervasive Development Disorder. Sometimes these disorders are categorized as a spectrum continuum disorder because the symptoms can range from mild to extreme. Basically, the sensory system for people with autism differs from others so that these children may react quite unusually to stimuli: people, objects and events.

\section{Youth with ASD}

Because ASD is manifested in so many different ways, it is difficult to ascribe blanket characteristics about these children. Nevertheless, some aspects may be examined with 
confidence. Because children may react quite unusually to stimuli, they may exhibit unusual repetitive behaviors, which are their mechanisms for dealing with stimuli. Some children have difficulty controlling their behaviors within a high-stimulus situation; not surprisingly, most children with autism prefer predictable routines and environments. They may have difficulty imagining the perspective of another person. It should be noted that empathy is very present in autistics; it just presents itself differently. These children may seem to prefer to be alone, tending not to express feelings of affection that are easy to interpret; for instance, they may well play side by side rather than interactively, which is their method of socialization. Speech development is usually impaired developmentally, although children with autism may communicate well in other ways such as images or typing. Linking ASD to children's sensory processing is a useful way to describe their behaviors. Another important consideration is the developmental aspects of children of ASD; they are growing individuals first of all. Furthermore, parental belief systems about lifestyles and treatment options can influence how they treat their autistic children - and interact with educational personnel.

\section{Youth with ASD in Library/Educational Settings}

Children with autism encounter challenges in libraries and other educational systems because they have impaired social and communication development. Social situations are very difficult because their social skills do not evolve naturally. Autism also affects children's thought, perception and attention span. Their body language often differs from children without autism, so the two parties may have problems "reading" each other. It should also be noted that people with autism tend to think literally, so metaphors and idioms can present problems. Current educational thought promotes an inclusion/mainstreaming model of education; nevertheless requires special attention is required because ignorance of ways to interact with these populations can result in frustration for all parties. Moreover, children with autism need more than an academic curriculum per se; they need socialization and observational skills.

\section{Inclusion Strategies (Universal Design) in Libraries}

Taking the approach of universal design, whereby material and digital resources are made accessible to all users including those with special needs, library programs should be accessible to all youth including those with autism. Facilities should include alternative seating and sensitivity to the child's body space so others touch will not affect sensory system or focus. The library door should be closed to eliminate outside noises. Natural lighting should be used since fluorescent lighting upsets some autistic children.

Here are some specific physical accommodations that can help students with ASD feel more comfortable:

- Strip of foam pipe insulation applied to edge of chair gives parameters of security and a closed in feeling.

- Masking tape around area on the floor that child is to sit in for circle time.

- Weighted vest: can be a fishing vest with pebbles if cannot afford to buy weighted vest.

- Weighted arms: Fabric with pockets on both ends to place weighted materials in such as marbles or pebbles wraps around shoulders and upper torso of student providing pressure and closed in feeling to soothe senses.

Because of barriers in library learning activities barriers, the need is underscored for the librarian to collaborate with classroom and daycare teachers and to design inclusive 
curriculum-based learning activities that include accommodations explicitly for special populations. Examples of inclusionary practices include: providing a consistent routine for library use and instruction; using singing and rhythm games helps get all children's attention; incorporating visual aids and body movement; giving children transitional signals.

\section{Resources}

One of the core aspects of libraries is the collection, organization, and access to resources. Content needs to build upon individual interests. Because this population engages in different ways to content, identifying and using information in a variety of formats is imperative; visual information is especially fruitful. In addition, resources that build on sensory experiences can lead to more effective engagement. As librarians choose resources, they need to consider the age and development of youth with ASD in order to optimize their engagement and learning.

Technology provides potentially effective resources and communication channels. Computer technology also extends children's attention span. In optimizing technology, librarians need to consider the critical features of technology, including their affective impact. Assistive technology, any device that can assist a person to adapt to a given skill, can help level the learning field of students with ASD. Some specific techniques include:

- Use documents that are literal and repetitive or rhythmic, and that include photos rather than drawings.

- Use a variety of formats: audiocassettes, software, toys, manipulatives.

- Take advantage of picture dictionaries and atlases.

- Enlarge texts and pictures to make them easier to see.

- Use visual rather than auditory stimulation.

- Incorporate Kid Pix and drawing-type software programs; these students are likely to get fixated on a thing or character.

- Use videotapes of a book that replicates the original, and used with the print copy.

- Show video clips that demonstrate positive behaviors in very concrete detail.

- Use software/web tutorials to teach skills; Reader Rabbit is a good example.

- Scaffold learning using technology.

Universal instructional and design principles help not only students with autism but all students.

\section{Teaching/Instruction}

Librarians should find out which children have special needs, and gain basic knowledge about ways to create a suitable learning environment for them. Instruction needs to be highly structured. Likewise, transitions between activities need to be transitioned explicitly. Age- and developmentally-appropriate issues also need to be considered. Of great benefit in reaching students with ASD, Pivotal Response Treatment uses both a developmental approach and applied behavior analysis procedures, and aims to provide opportunities for learning with the context of the child's natural environment. Another effective method is ABA (Applied Behavioral Analysis). Appropriate course of action should include curriculum adapted by either resource teachers or Special Day Class teachers.

\section{Learning Activities}

Librarian should encourage youth with ASD to be involved in library experiences alongside their peers, building on their strengths and interests. Scaffolding can help youth 
learn appropriate language relationships. For example, asking binary questions (e.g., "Did he eat a cake or a cookie?") and literal discrete questions enable children to develop communication skills. Technology can help learning by providing highly structured learning activities that can be repeated and paced according to individual need, requiring little social interaction. To help ASD youth socialize, librarians should find out which peer or aide is paired the child with autism, and instruct them to sit near the librarian to reduce distractions and anxiety. Age- and developmentally-appropriate issues also need to be considered. Librarians also need to involve NPA (non public agency) aides.

\section{Sample Library Activities}

The following library activities have been tested successfully with students with ASD.

- Use dolls/puppets. Examples: Little Red Riding Hood doll with red jacket, stuffed wolf animal, and Grandma doll. While telling story, have autistic students arrange tactile items in order. Activity keeps students both on track and focused while fulfilling need to line up items both mentally and physically to increase comprehension.

- Encourage communication and student interaction by asking students which items are bigger, rougher vs. smoother, and color. This gives children choice of answers instead of having to communicate spontaneously, which is much harder especially in groups. It gives children success in large group and amongst peers boosting self esteem, increasing likelihood of further spontaneous academic attempts.

- "Into" activity. Show movie clip of story such as Sponge Bob DVD before reading Sponge Bob book. Students engage in conversation and contact by hearing beginning theme music and seeing characters come to life.

- Have an activity bag with props from the story for autistic student. Have the autistic child sit on the side of the class so as not to distract peers.

- How Are You Peeling is a great literal book with pictures and gives conversation opportunities to discuss feelings, which is difficult as it is spontaneous speech. Have a bag of small vegetable with faces. A learning center afterward can have vegetables with Mr. Potato Head mouths and ears that can be stuck into vegetables in order to repeat learned emotions and replicate pictures from text.

- Autism Acceptance Book (Ellen Sabin). Educate peers to appropriate levels of defining autism so they can comprehend and be the student's special friend who can be a helper if they need it. Sample activities: Intro for class peers: take sensory empathetic survey (p. 19). Photocopy walk in their shoes (p. 27). Make poster (p. 15). Make class work sheet (p. 14). Define social stories (p. 6).

- Word Walk. Find repeated phrases from book to be used in library. Write each word of that phrase on 8 " x 11 " paper. Make a paper path from library door to circle time area. Students walk and read the word path giving autistic students opportunity to have tactile decoding comprehensive experience while meeting sensory needs and increasing comprehension.

- Library treasure hunt. Place props from stories in library. Give students a very basic map. They must go to each area in the library find object, and mark off " $\mathrm{X}$ " in box by area found. An example is a Halloween Hunt: "Look for the witch and her broom. She flies in corners near the edge of the room." Students then look for a flying witch doll hanging from the ceiling in the corner of the room. Map can include photographs of items being sought after.

- Autistic students excel at decoding words and being lexographic. If an autistic student can read in front of peers, their comprehension will not equal their peers but their 
decoding skills will likely excel their peers. Give autistic students opportunities to recast repetitive phrases in book, reading it in front of their peers. This boosts their self-esteem, integrates them socially, and involves them in lesson equally with other students instead of being on the sidelines told to be quiet and sit still, both of which are hard for many autistic students.

- Pair books to tactile items that can relate to objects: Rice table: Grandfather's Dream and Indian counting tale; Tinker toys: The House that Jack Built; sand table: Grandma and Me.

- Learning Stations. Pair students up to explore learning centers together in LMC. A sample interactive activity would be write down name of train (from name on bottom of each train), and draw the same face train does on piece of paper (Thomas trains all have faces that show definite emotions of how the trains are feeling). Group can discuss emotions with classroom teacher later as part of $\mathrm{LMC} /$ classroom teacher collaboration.

\section{Focus on Hyperlexia}

One focus of library service for this population should be reading, particularly since some students with ASD exhibit hyperlexia, which is a syndrome observed in children who have the precocious ability to read words. These students have significant difficulty understanding and using verbal language or a significant nonverbal learning disability, and they have difficulty in reciprocal interactions; in other words, they have the ability to decode words and text at very advanced levels without the ability to comprehend the meanings of those words that are being decoded.

Librarians need to select books that appeal to autistic children: repetitive/predictable elements, rhyme, familiar sequences, question/answer format, chain or circular story. There are several techniques to make books more accessible: laminating pages, enriching texture, purchasing books with real photos, locating books that are about autistic children, including the autistic student's opinion in library book acquisitions.

Noted how autistics respond to literacy and library skill instruction both in one to one and group instruction, librarian should make use of NPA-trained aides. Librarian need to figure out ways to engage autistic children with choice questions, including the use of technology. Librarians should also understand how to interpret Echolalic Responses to literature and reading stimulus. To optimize learning, teacher librarians should consider using a team approach: of classmates, other school personnel, and families.

\section{Social Strategies}

Probably the most effective way to engage students with ASD is to get to know each child on a personal basis. Librarians also need to get to know other adults who work with this population and parents of youth with ASD. To optimize socialization in school settings, librarians should prepare the following groups to work with students with ASD: the ASD student him/herself, library staff and aides (including students), other students, other teachers/school community members, and the child's and other parents.

\section{Sensory Overload Leads to Self -Stimulating Behaviors}

- If the autistic child begins rocking, flapping suddenly or has sudden amount of increased repetitive speech or any other sudden obsessive behaviors, he/she is 
experiencing sensory overload. Is it the lights, the clothes, the noise, the proximity of other students, aide or teacher?

- Have the aide take the student away from group temporarily to adjust for the sensory issue. Need sunglasses, sit further away from children, pressure squeeze to body, less noise, etc.

- When giving an autistic child praise, be attuned to volume and proximity.

- If the class is applauding for each other; use a distant golf clap after the ASD student excels instead of class clapping.

\section{Behavior Modification}

- If the ASD student is in a loop of verbal obsession with an item or phrase, recast the phrase adding pronoun in an interrogative format. Example: Sponge Bob and Patrick have crabby patties in Bikini Bottom. Recast: "Do you eat crabby patties with Patrick and Sponge Bob? I like to eat crabby patties with Patrick and Sponge Bob." Or have the student write the sentence; if unable; the librarian writes the sentence and reads it several times with student. When the librarian shares in their students' obsessive thought, it tends to fulfill the sensory need and they are more able to move forward to their next thought.

- If the ASD child repeatedly asks disruptive questions, such as "Is it time for lunch" while at story time, draw 3 boxes on paper. Tell the student they get to ask the same question 3 times. Put a check in the box each time that they ask. After they have asked 3 times, they are not allowed to ask any more.

- Coping tools for sensory defensiveness. If classroom noise is too overwhelming for student initially, desensitize by taping class noise, and loaning tape to parents to play at home in small infrequent amount, then gradually increasing time periods.

- Visual Schedule. Have a large schedule that hangs on wall behind the librarian. This gives the autistic student clarity and makes transitions easier. Unexpected, unpredictable transitions guarantee poor behavior and tantrums.

1. Have large photographs of students sitting in circle time listening to story. 2. Have next picture of students at book/tactile learning centers. 3. Next picture of students checking out books at circulation desk. 4. Final picture of students lined up at Library door ready to leave for class.

\section{Group Dynamics}

- The librarian sets an example by retelling the story. Autistic student then repeats the librarian's story. The librarian asks the autistic student to retell initially just the beginning of story. By the end of school year the goal would be to have autistic student in a minimum of 1 sentence/response be able to recast story in their own words. For example, the librarian asks, "Where did Little Red Riding Hood go in the beginning of the story? Acceptable response is "She went to Grandma's house, or she walked in the woods." Limited unacceptable response: "Away." Encouraging comprehension through recasting or echolalic (echoing) natural tendency is fine. It will make the student feel comfortable enough to eventually expand out to 3-4 word phrase responses.

- When reading stories to students, leave out the last word or key phrase when it is predictable. Let all students fill it in together by repeating predictable phrase as class. This gives students cohesive social experience while allowing the autistic student increased comprehension and doesn't force them to sit without movement or speech. 
Sample books with repetitive response: This is the House that Jack Built, King Bidgood's in the Bathtub (Don Wood), It Looked Like Spilt Milk (Charles Shaw), A Dark, Dark Tale (Ruth Brown), The Doorbell Rang (Pat Hutchins).

\section{Home Connections}

Family relationships with their ASD children affect library experiences. Librarians can help parents and grandparents provide an effective learning environment, and choose appropriate resource for their children. Families who visit the library together provide opportunities for librarians to observe their interaction and work with them effectively. Teacher librarians, in particular, can suggest effective strategies to help parents improve their children's cognitive and social skills.

\section{Training}

Library staff and the school community at large need training in order to understand the nature of students with autism, and to suggest effective ways to serve this population. Each target group needs to explore different content, and be approached in different ways. Each also needs unique resources. In any case, by becoming more knowledgeable about these children, the entire library staff - as well as student aides and adult volunteers - can provide a safe and appropriately stimulating learning environment for these children and model inclusive social education. Elements of training should include:

- Assess staff's current knowledge and practice.

- Increase staffs' knowledge about Autism Spectrum Disorder and the typical behaviors of children in regards to expected behaviors in the academic environment.

- Provide sample library lessons for inclusion of special needs children from ERIC, such as Mitten Math and Locating Library Books (How to alphabetize).

- Brainstorm accommodations.

- Provide bibliography of library books and other resources that would be of specific interest to students with ASD.

- Have experts on Autism provide staff in-service in PRT Pivotal Response Training (very easy to learn and no cost to implement).

\section{Measuring the Impact}

In order to determine what interventions impact learning, both for youth with ASD as well as their peers, librarians need to be reflective practitioners, using action research to demonstrate their effectiveness. Once librarians determine their objective, they can conduct their action research: determining what to measure and why, identifying appropriate assessment tools, gathering and analyzing data, and acting on their findings.

\section{References}

Adams, J., Edelson, S., Grandin, T., \& Rimland, B. (2004). Advice for parents of young autistic children. Tempe, AZ: Arizona State University.

Akin, L., \& MacKinney, D. (2004). Autism, literacy, and libraries. Children \& Libraries, 2(2), 35-43.

American Psychiatric Association. (1994). Diagnostic and Statistical Manual of Mental Disorders, DSM-IVTR. Washington, DC: American Psychiatric Association. 
Anixter Center. (2004). National Lekotek Center. Chicago: Anixter Center. http://www.anixter.org/mediaroom/divisions/lekotek.htm.

Banks, C. (2004). All kinds of flowers grow here: the child's place for children with special needs at Brooklyn Public Library. Children \& Libraries, 2(1), 5-10.

Behrman, S. (1987). Autistic teen takes to library work: NYPL center teaches marketable skill in school sponsored project. American Libraries, 18(5), 375.

Bellon, M., et al. (2000). Repeated storybook reading as a language intervention for children with autism. Focus on Autism \& Other Developmental Disabilities, 15(1), 52-58.

Bettelheim, B. (1967). The empty fortress: Infantile autism and the birth of the self. New York: The Free Press.

Broun, L. (2004). Teaching students with autistic spectrum disorders to read: a visual approach. Teaching Exceptional Children, 36(4), 36-40.

Centers for Disease Control and Prevention. (2006). Autism. Atlanta: Centers for Disease Control and Prevention.

Colasent, R., \& Griffith, P. (1998). Autism and literacy: Looking into the classroom with rabbit stories. Reading Teacher, 51(5), 414-420.

Dunlap, G., \& Fox, L. (1999, Oct.) Teaching Students with Autism. ERIC Digest. Reston, VA :ERIC Clearinghouse on Disabilities and Gifted Education. (ERIC Identifier: ED435148).

Feinberg, S., et al. (1999). Including families of children with special needs: A how-to-do-it manual for librarians. NY: Neal-Schuman.

Gus, L. (2000). Autism: promoting peer understanding. Educational Psychology in Practice, 16(3), 461-468.

Iovannone, R., Dunlap, G., Huber, H., \& Kincaid, D. (2003). Effective educational practices for students with Autism Spectrum Disorders. Focus on Autism \& Other Developmental Disabilities, 18(3), 150-165.

Kamps, D., et al. (2002). Peer training to facilitate social interaction for elementary students with autism and their peers. Exceptional Children, 68(2), 173-187.

Koegel, L. (2004). Overcoming autism. New York: Viking.

Koegel, R. (1989). How to teach pivotal behaviors to children with autism: A training manual. Santa Barbara, CA: University of California.

Koegel, R., \& Koegel, L. (Eds.). (1995). Teaching children with autism: Strategies for initiating positive interactions and improving learning opportunities. Baltimore: Brookes.

Koppenhaver, D., \& Erickson, K. (2003). Natural emergent literacy supports for preschoolers with autism and severe communication impairments. Topical Language Disorders 23(4), 283-292.

LeComer, L. (2006). A parent's guide to developmental delays: recognizing and coping with missed milestones in speech, movement, learning, and other areas. New York: Perigee Putnam.

Library Service to Special Population Children and Their Caregivers Committee. (2004). Children with disabilities and library programs. Chicago: Association for Library Services to Children . http://www.ala.org/ala/alsc/alscresources/forlibrarians/Chldrnnwithdisabilities.htm.

Ludke, L. (2002). Expanding the circle: an outreach program tailored to children with special needs. School Library Journal, 48(10), 41.

Maurice, C., Green, G., \& Luce, S. (Eds.). (1996). Behavioral intervention for young children with autism: A manual for parents and professionals. Austin, TX: PRO-ED.

Neumann, H. (2003). What teacher-librarians should know about universal design. Teacher Librarian, 31(2), 17-20.

Olley, J. (1999). Curriculum for students with autism. School Psychology Review, 28(4), 595-607.

Pallaske, M. (2006). What's Your "A.Q?" (Autism Quotient Quiz). West Salem, WI: Cooperative Educational Service Agency \#4. http://www.cesa4.k12.wi.us/programsservices/special/autism/quiz.htm.

McClannahan, L., \& Krantz, P. (1999). Activity schedules for children with autism: Teaching independent behavior. Bethesda, MD: Woodbine.

Morimoto, J. \& Fox, M. (1999). Literacy is for everyone: Making library activities accessible for children with disabilities. Lincolnwood, IL: National Lekotek Center.

Shabani, D., Katz, R., Wilder, D., Beauchamp, K., Taylor, C., \& Fischer, K (2002). Increasing social initiations in children with autism: effects of a tactile prompt. Journal of Applied Behavior Analysis, 35(2), 79-83.

Shriver, M., Allen, K., \& Matthew, J. (1999). Assessment and treatment of children with autism in the schools. School Psychology Review, 28(4), 535-537.

Talay, A. \& Wood, K. (2000). Unusual sensory sensitivities in autism: a possible crossroads. International Journal of Disability, Development and Education, 47(2), 201-212.

Thiemann, K., \& Goldman, H. (2004). Effects of peer training and written text cueing on social communication of school-age children with Pervasive Developmental Disorder. Journal of Speech, Language \& Hearing Research, 47(1), 126-144. 
Usabel, F., \& Swanson, C. (1999). Public library services for youth with special needs: A plan for Wisconsin Madison, WI: Wisconsin Department of Public Instruction.

Wesson, C., \& Keefe, J. (1995). Serving special needs students in the school library media center. Westport, CT: Greenwood Press.

Wilder, L., Dyches, T., Obiakor, F., \& Algozzine, B. (2004). Multicultural perspectives on teaching students with autism. Focus on Autism \& Other Developmental Disabilities, 19(2), 105-113.

\section{Biographical Notes}

Dr. Lesley Farmer, Professor at California State University Long Beach, coordinates the Librarianship program. She earned her M.S. in Library Science at the University of North Carolina Chapel Hill, and received her doctorate in Adult Education from Temple University. Dr. Farmer has worked as a teacher-librarian in K-12 school settings as well as in public, special and academic libraries. Dr. Farmer serves as IASL VP for Association Relations, chairs the Education Division of Special Library Association, and participates actively in other professional organizations. A frequent presenter and writer for the profession, Dr. Farmer's most recent books are Information Literacy Assessment in K12 Settings (Scarecrow Press, 2007) and Teen Girls and Technology (American Library Association, 2008). In 2007 she received a Distinguished Scholarly and Academic Achievement Award from her campus, and was selected as California Library Association Member of the Year. Her research interests include information literacy, collaboration, equity in library services, and educational technology.

\section{Statement of Originality}

This statement certifies that the paper above is based upon original research undertaken by the author and that the paper was conceived and written by the author(s) alone and has not been published elsewhere. All information and ideas from others is referenced. 